Stefan N. Grösser • René Zeier

Editors

\title{
Systemic Management for Intelligent Organizations
}

Concepts, Models-Based Approaches and Applications

Springer 


\section{Contents}

\section{Part I Methodology}

1 Cybernetic Management Paradigms . . . . . . . . . . . . 3 Matthias Hühn

2 The Importance of Being Atheoretical: Management

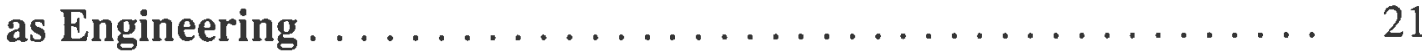
Camilo Olaya

3 What Is a Validation Methodology? Analyzing and Synthesizing Two Meanings . . . . . . . . . . . . . . . . . . . . . . .

Stefan N. Grösser

Part II Management

4 The Management of Strategic-Foresight Activities: Evidence from Large European Multinationals . . . . . . . . . . . . . 63 Günther Müller-Stewens, Adrian Mueller, and Veronika Lüders

5 More Foxes in the Boardroom: Systems Thinking in Action ...... 83 Peter Gomez and Timo Meynhardt

6 The Management of Innovations and Personal Well-being:

A Trans-Disciplinary Model and Empirical Findings . . . . . . . . 99 Andreas Krafft

7 Can a Cybernetic Approach Help Build Intelligent Organizations? A Critical Inquiry . . . . . . . . . . . . . . . . . . 121 Andrea L. Sablone 
Part III System Dynamics

8 Enhancing Performance Management and Sustainable

Organizational Growth Through System-Dynamics Modelling . . . . 143 Carmine Bianchi

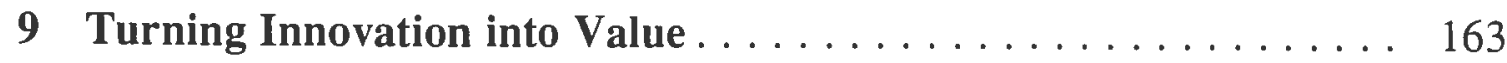
Henry Birdseye Weil

10 System Dynamics in Distressed Investments: Power and Limitations from the Perspective of a Project Manager . . . . . . . . . . . 179 Marius Fuchs

11 Application of Systems Thinking in Management Consulting . . . . 195 Thomas K. Hamann

Part IV Viable System Model

12 Organizational Cybernetics and Urban Planning: The Case of the University of A Coruña . . . . . . . . . . . . . . . . 211 José Pérez Rios and Xosé Lois Martínez Suárez

13 Reffections on Adequate System Variety . . . . . . . . . . . . . . 227 René Zeier

14 Sustainable Governance . . . . . . . . . . . . . . . . . . . . . . 237 Ralf-Eckhard Türke

15 Business Intelligence and Second-Order Cybernetics: The Importance of Knowledge Management . . . . . . . . . . . . 249 Peter Hechenblaickner

List of Authors . . . . . . . . . . . . . . . . . . . . . . . . . . 269 


\title{
Chapter 4
}

\section{The Management of Strategic-Foresight Activities: Evidence from Large European Multinationals}

\author{
Günther Müller-Stewens, Adrian Mueller, and Veronika Lüders
}

\begin{abstract}
Despite the strategic relevance of strategic-foresight activities, the strategic-management literature contains only little and fragmented knowledge of how firms successfully manage such activities. This exploratory paper provides insights into the management of strategic-foresight activities based on in-depth case studies of five large multinational companies. According to our findings, strategicforesight activities (1) are structurally managed within an organization via one of three models, (2) consist of initiation, modeling, and finalization phases, which occur in circular, iterative loops, (3) use increasingly qualitative and participative methods, (4) support strategic decision-making with a main focus either on innovation and exploration or on planning and exploitation, (5) are subject to substantial change depending on the content-related openness of the corporate strategy (diversification vs. focusing) and the openness of the strategic-planning process (outside vs. inside orientation), and (6) are induced by a radical and sudden change in the corporate strategy.
\end{abstract}

Keywords Strategic Management $•$ Forecasting $\bullet$ Environmental Analysis • Issue Management • Early Warning Systems • Grounded Theory

\section{G. Müller-Stewens}

IFB Institute of Management, University of St. Gallen Dufourstrasse, 40a CH 9000, St. Gallen e-mail: guenter.mueller-stewens@unisg.ch

\author{
A. Mueller \\ Zurich University of Applied Sciences St. Georgenstrasse, 70CH 8400, Winterthur \\ e-mail: adrian.mueller@zhaw.ch \\ V. Lüders \\ Lochbrunner Consulting Hermannstraße, 11D 33602, Bielefeld \\ e-mail: vl@lochbrunner-consulting.de
}




\subsection{Introduction}

In strategic management, it is critical to gain insights into future developments in a firm's external environment. This is because firms must change in accordance with environmental dynamics (Suarez and Oliva 2005). The absence of an appropriate response can lead to a performance decline and ultimately threaten a firm's survival. In most management frameworks and models, which are understood as representations of a real system, at least one component is devoted to anticipating the environment so as to increase an organization's intelligence and viability (Schwaninger 2010). For example, according to Stafford Beer's Viable System Model, (1972) System 4 is responsible for monitoring the socio-economic environment so as to estimate how the company must adapt in order to stay viable and survive as a system.

Strategies are based on assumptions about the environment. These days, many assumptions are either changing or likely to change. Subsequently, managers are looking for ways to go from these new developments to their corporate strategy (Ruff 2006; Becker and Freeman 2006). In response to such increasingly uncertain and dynamic external environments, many firms have established sophisticated management systems in order to increase their organizational intelligence by carrying out strategic-foresight activities.

Exploring future developments has been a key aspect of strategic management since its inception (Hoskisson et al. 1999). The central related concept has been strategic issues (Ansoff 1980; Dutton and Duncan 1987; Elenkov 1997; El Sawy and Pauchant 1988; Thomas and McDaniel 1990), which are defined as "developments or trends that emerge from an organization's internal or external environment; they are perceived to have the potential to affect an organization's performance" (Dutton and Ottensmeyer 1987: 355). The activities that are implemented in order to deal with strategic issues are termed strategic-issue management (Oomens and van den Bosch 1999), and the systems for carrying out such activities, strategic-issue management systems.

A related, more recent concept describing an organization's involvement in estimating and compensating for future issues is foresight, which has recently been gaining much attention in the academic and corporate world (Tsoukas and Shepherd 2004). Twenty-five years ago, Lederman (1984: 41) described organizations' then-current systems for carrying out foresight activities as "relatively recent, still evolving, and [...] under review in the hope of improving their effectiveness," while today, foresight activities and their management are a central part of many large corporations' strategic-management systems. Moreover, they are critical to the strategic decision-making and ultimately the success of these organizations (Gruber and Venter 2006). In particular, firms in industries with a long-term orientation, such as the oil or chemicals industries, are highly dependent on future knowledge estimates. Therefore, they have established sophisticated systems for managing their foresight activities. Despite this development and the critical importance of foresight, knowledge of how to manage foresight activities is still limited and fragmented within the strategic-management literature. 
Our central research question is: How do corporations align their strategic foresight activities and processes with their changing internal and external contexts? This paper subsequently contributes to strategic-management research by describing how large corporations manage their strategic-foresight activities over time. In particular, it focuses on showing how strategic foresight is integrated into strategic decision-making, and how the management of strategic-foresight activities is aligned with changes in corporate strategy. The findings are based on in-depth case studies of five large multinational companies' foresight activities. The headquarters of all five companies are in the German-speaking area of Europe.

This paper is organized as follows: Sect. 4.2 lays out the theoretical background of the research, specifying the concept of strategic foresight and giving a short review of the literature on the management of strategic-foresight activities. Section 4.3 explains the methodology used for this study, while Sect. 4.4 presents the research findings. Finally, the conclusion provides a brief summary and critique of the findings, and discusses the findings' implications for future research.

\subsection{Literature Review}

According to Beer (1972) as well as Chakravarthy et al. (2003), organizations must constantly scan their business context in order to proactively renew their strategic purpose. Likewise, Chakravarthy, and White (2002: 189) propose: "Foresight and vision, not just rationality, are important drivers of a firm's strategy. Besides feedback learning, feed-forward learning (foresights about a firm's external environment) influences decisions and actions within a firm and through them its strategy."

Strategic-issue management has focused on future threats and opportunities (Ansoff 1980), i.e., on the search for particular strategic issues. Hence, it is often characterized by a relatively focused and narrow perspective on specific future issues. In contrast, strategic foresight intends to create a relatively broader and more open picture of the future. Moreover, it integrates its conceptions, approaches, and tools to support strategic decision-making, and initiates planning and innovating activities in organizational contexts. According to Burmeister et al. (2004), foresight has three central tasks in an organizational and strategic setting: The preparation of strategic decisions, the long-term securing of an organization's competitiveness, and the permanent strengthening of the organization's ability to learn and innovate.

Systems theories and cybernetics take a different view. They argue that the purpose of strategic foresight is to make organizations more intelligent. An organization is considered intelligent if it adapts its functions according to external stimuli and, in turn, influences and shapes its environment (Espejo et al. 1996). This means that a system and its environment mutually affect and change each other (Schwaninger 2009). 
Various definitions of foresight have been proposed (Costanzo and MacKay 2009). Becker (2002: 7) describes it as a process: "Foresight should be understood as a participatory, future intelligence-gathering and medium-to-long-term visionbuilding process that systematically attempts to look into the future of science, the economy and society in order to support present-day decision-making and to mobilize joint forces to realize them." Tsoukas and Shepherd (2004b: 10) see it as a specific capability: "Foresight marks the ability to see through the apparent confusion, to spot developments before they become trends, to see patterns before they fully emerge, and to grasp the relevant features of social currents that are likely to shape the direction of future events." In light of the existing definitions, we have developed our own definition of strategic foresight for this study, which is strongly focused on the process perspective of foresight, i.e., foresight activities. We define strategic foresight as a participatory process with the objective of supporting strategic decision-making through the anticipation, analysis, and interpretation of long-term trends in and scenarios of a company's socio-economic environment. Consequently, we define strategic-foresight activities as the actions taken within a strategic-foresight process.

To gain a better understanding of how "strategic foresighting" occurs in organizations, we first scan the literature on strategic foresight for different process types, i.e., the ways in which strategic-foresight activities can support strategic decision-making. Second, we examine different process-phase models that describe possible strategic-foresight process sequences. Third, we briefly discuss the methods that are used in strategic-foresight processes.

Process types: We can identify three approaches (Cunha et al. 2004; Lüdeke 2007): Foresight as environmental analysis, foresight as learning, and foresight as visionbuilding.

First, strategic foresight can be understood and designed as a process to analyze the environment. Consequently, it is essential to collect important information about current developments in the corporate environment. The objective is to prepare organizations for future developments, discontinuities, and surprises in their environment in order to reduce decision-making time. According to this understanding, strategic foresight is primarily concerned with probable futures. The future is therefore anticipated in an exploratory manner, based on an "outside-in" analysis of the environment and the early detection of "weak signals" (Ansoff 1965). The design of the foresight process is primarily focused on the construction and functioning of management systems with regard to the collection and processing of information.

The second approach to strategic foresight has been shaped mainly by studies of "scenario processes" (Schwartz 1991; Wack 1985). In these, foresight is seen as an open learning process in which the organization reflects upon its business and strategy against the background of different future scenarios. Based on these scenarios, future opportunities and threats are identified. This mainly involves externalization and the challenge of existing paradigms, which lead to feed-forward learning: "The purpose is to explore an as yet unexplored problematic situation. Deciding an intervention is not part of this foresight project. Instead we aim for 
sensitizing, reframing, surfacing assumptions, making sense, 'seeing', anticipating" (Van der Heijden 2004: 9).

Finally, strategic foresight can be regarded as a process of a vision's normative formation, which is geared toward the creation of a shared belief about both the future and the organization's objectives (Grosu 2007). Consequently, creativity and focusing on a common goal are paramount. The main functions are the generation and alignment of preferences, and mobilization towards the achievement of common goals and visions. The organization's environment is considered influenceable. The goals of strategic foresight are to create an inspiring culture, to enable mindful exploration, and to shape desirable futures (Godet 2001). The central concept is "visioning" (Collins and Porras 1996).

Process-phase models: The literature on strategic foresight identifies three different conceptualizations of process phases in strategic foresight. In these studies, the process is usually conceptualized as a linear foresight process consisting of three consecutive phases.

Horton (1999) bases his conceptualization on the analysis of different national foresight programs, as well as on academic literature in the areas of futures-research studies and knowledge management. The foresight process consists of three phases: Phase 1 encompasses the collection, critical analysis, and summary of available information about the environment, and closes with the generation of futureoriented knowledge. Phase 2 is the core of the foresight process, encompassing the translation and interpretation of this knowledge. The objective is to realize the central implications for the organization's future(s). Phase 3 includes the implementation of this understanding and its integration ("assimilation" and "commitment") into individual and organizational action. According to Horton (1999: 9), the value-creation process in these three phases consists of different levels. Moreover, he stresses the following aspects: "Foresight is about a value chain of information, knowledge and understanding; it is understanding which will give rise to real value; going through the process can be as valuable as the results obtained; deriving value from foresight requires getting to the end of the whole process and taking the required actions; organizations must do this for themselves; outsiders can add value as catalysts and perhaps as temporary resources."

Major and Cordey-Hayes (2000a, b) describe strategic foresight as a knowledgetranslation process. In the first phase, i.e., "codification," concrete, strategically relevant information about the environment is collected and translated into longterm knowledge. In the second phase, i.e., "translation," this knowledge is transformed into an operational and decision-oriented understanding. The new wisdom can be used only as a concrete basis for decisions and actions in the third phase, i.e., "contextualization." Major et al. (2000a) explicitly stress that strategic decision-making and action require this concrete and short-term oriented form of knowledge. Strategic-foresight processes should thus follow the entire knowledge transformation process: "The firms that are best at foresight successfully bring external abstract-strategic knowledge into their internal tangible operational sphere. The very nature of a foresight process translates difficult-to-use external knowledge into useable internal knowledge" (Major et al. 2000b: 422). 
Voros's (2003) process model conceptualizes strategic foresight as a three-step process with an input, a foresight, and an output phase. During the input phase, strategic information is collected through various methods. Three "analysis," "interpretation," and "prospection" steps follow. During the analysis step of this phase, the collected data are evaluated for the first time. During the interpretation step of this phase, this information is subjected to an in-depth analysis and is reflected upon in the context of the company. In the prospection step of the phase, probable, possible, and desirable scenarios and images of the future are generated. Voros (2003) identifies explicit-formal and implicit outputs in foresight processes. The former are concrete strategic options. The latter are changes in decision makers' mental models (Slaughter 1995). At the interface between the foresight process and strategy development, the foresight-process outputs are simultaneously inputs for strategic decision- making and action. "The foresight process simply provides input into the consideration of decisions and the implementation of actions, which is the role of traditional strategy work" (Voros 2003: 13).

Process methods: The literature provides us with some information about the methods applied in strategic foresight processes. Evidently, the methods that are used in the system are crucial to strategic-foresight systems. However, no specific set of tools has been developed for strategy-foresight systems. Instead, methods from different scientific disciplines are chosen in a pragmatic way (Aaltonen and Sanders 2005). Naturally, the selection and use of methods strongly depend on the situation in which they are applied.

The methods typically used for strategic foresight activities are (Gordon 1994): trend analysis, decision analysis/models, the Delphi method, econometric models, mind mapping, gaming/simulations, genius forecasting, morphological analysis, participative methods, relevance trees, scenarios, statistical modeling, dynamic modeling, structural analysis, technology-series analysis, time-series analysis, trend-impact analysis, wild cards, and road mapping.

One challenge of using these methods is to link them together. Schwaninger (2001), for example, shows how systemic approaches can help link these methods, thus contributing to strategic foresight. He integrates three models from organizational cybernetics into a framework in order to trace a path toward excellent organizational intelligence: The model of systemic control, the Viable System Model, and the Team Syntegrity model.

In general, there has been an increase in the use of qualitative methods, mainly because they offer some degree of security (Burmeister et al. 2004). Moreover, while searching for strategies that are resilient to different future situations, we observed a strong demand for scenario analysis. This type of analysis helps one to ask the right questions and prepare for the unexpected (Roxburgh 2009).

In recent years, various studies have investigated the use of strategic trends and futures studies in firms (Kreibich et al. 2002; Steinle 2000). Most of them have been descriptive, cross-sectional studies based on surveys or interviews. More in-depth case-study research was conducted in only two case studies (Gruber et al. 2006; Van der Duin 2006). Most of the studies investigated large European enterprises, and in them the results vary greatly. In addition to the description of certain design aspects 
of strategic-foresight systems, the studies focus on drivers, strengths, weaknesses, and problem areas, as well as the potentials of studies in strategic trends and futures in corporations (Burmeister et al. 2002; Major et al. 2001). Furthermore, some areas of design are more frequently examined than others, such as usage, organizational integration (Becker 2002; Schwarz 2006), and time and planning horizons (Kreibich et al. 2002; Steinle et al. 2000).

Hence, previous studies have focused either on a high-level conceptualization of the strategic foresight process, or on more concrete, albeit single aspects of the management of strategic-foresight activities, especially design aspects. Up to now, the research has lacked a comprehensive description of the management of strategic foresight-activities from a process perspective.

We aim to "dig deeper," to gain a better understanding of how foresight activities are actually managed. Moreover, we are particularly interested in how strategic foresight influences strategic decision-making, and how foresight is integrated into such decision-making. We are particularly interested in how firms change the management of their foresight activities in response to a change in their corporate strategy.

\subsection{Data and Methods}

\subsubsection{Research Approach}

To investigate how strategic foresight activities are managed, integrated into strategic decision-making, and aligned with changes in corporate strategy, we adopted an inductive design and exploratory methodology to gain new insights instead of using formal hypothesis testing. We did so for two reasons: First, one of our major goals was to gather data on the contemporary management of strategic foresight-activities in large corporations and how they change over time. Second, there is little theory on the management of strategic-foresight activities. Hence, an inductive research design was suitable.

Most studies of strategic foresight have used questionnaire data. However, this method does not allow for capturing the richness and complexity of companies' foresight activities. To gain deeper insights into how companies manage and integrate strategic-foresight activities and how these activities change over time, we adopted a comparative case-study approach. Since our research did not involve hypothesis testing, and because the goal was to identify commonalities between companies' strategic-foresight practices rather than analyze cross-sectional differences, the disadvantages of case-study research regarding the limited research sample were less critical. 


\subsubsection{Data Collection}

In collecting data we proceeded as follows: First, we identified five companies that fulfilled the selection criteria and also agreed to cooperate. We selected these companies based on five criteria: First, the companies had to be of a certain size, which we defined as a yearly turnover of at least 150 million Euros. Since formalized foresight activities require substantial personal and financial resources, we assumed that primarily large enterprises would invest these resources in formalized strategicforesight activities. Second, an internal strategic-foresight unit had to have been in place for a minimum of 5 years. An in-depth investigation of strategic-foresight activities and a retrospective observation of their contextual alignment processes require that the staffs in question have experience with these activities. Third, the foresight activities had to be a high level of formalization. This criterion guarantees that the organizational and methodological status of the development is high, which is needed for investigations such as ours. Fourth, the company's headquarters had to be located in Europe. This criterion was added to ensure that the company was accessible. Finally, a strong willingness to cooperate was required, as this is an important precondition for generating rich empirical data and knowledge. Departments in five of the corporations identified and approached by means of these criteria agreed to participate in the study: DaimlerChrysler's Society and the Technology Research Group (DC STRG), TUI's Corporate Research \& Innovation (TUI CRI), BASF's Strategic Planning \& Controlling (BASF SPC), Deutsche Bank (Research)'s Macro Trends Team (DBR MTT), and Hilti's Corporate Development (Hilti CD).

Second, interviews were arranged with the person responsible for strategic foresight, as well as other persons closely involved in foresight activities. Here it was important to arrange interviews with managers who had enough experience in the firm, so that we could discuss the development of foresight management over the years. Eighteen semistructured interviews were conducted, i.e., three or four per company, each lasting between 30 and $250 \mathrm{~min}$. Notes were taken during the interviews. The interviews were recorded and transcribed, and full reports of the interviews were written up immediately after each interview. The interviews covered the following areas:

- The historical development of the company's foresight activities, including important phases of change;

- The current strategic-foresight system, including the organizational integration, the design of processes and structures, the relation of strategic-foresight activities to strategic decision-making, as well as the predominant cultural aspects related to strategic foresight; and,

- The alignment processes, for which we focused on what the interviewee considered the three most important changes in strategic-foresight activities during the past years. These included changes in the foresight activities themselves, as well as changes in the context that induced a given change.

Interview data were supplemented with information from case studies, research papers, company reports, and documents. These were particularly useful sources of historical data on the companies' strategic processes. 
Third, a case study describing each company's strategic foresight activities was prepared. Where gaps and inconsistencies were apparent, the interviewees were approached again to provide clarification or additional information. We followed Eisenhardt's (1995) recommendations for case-study research.

\subsubsection{Data Analysis}

In our data analysis, we focused on obtaining descriptive information.

In analyzing our data, we followed the grounded-theory approach for inductively building new theory. "The grounded theory is a qualitative research method that uses a systematic set of procedures to develop an inductively derived grounded theory about a phenomenon" (Strauss and Corbin 1990: 24).

Consequently, the coding process was of particular importance. We first undertook a "with-in case analysis" to generate a deep understanding of each case. Thereafter, using the "constant comparative method," we undertook a comparative "cross-case analysis" (Strauss et al. 1990). Three types of coding were applied in an iterative way. We later used a step-by-step approach, proceeding from open coding, which resulted in codes, to axial coding, which resulted in axial categories, and finally to selective coding, which resulted in core categories. The data sources for the coding process were interview transcripts, single case reports, and a selection of firm-internal documentary data.

To manage the data during the process, as well as for later retrieval, a case-study database was developed with the support of Atlas.ti, a qualitative software tool. This tool supported the aggregation of codes into respective higher-level categories of net codes. For the analysis of each case, we present an overview of the development of each studied company's foresight activities, the key events, and the shifts over time. The most relevant criteria of all five companies were compared in a cross-case analysis (Müller and Müller-Stewens 2009: 167-212), which led to the following results and insights.

\subsection{Results}

To answer our research question, we structured our findings on the management of strategic-foresight activities along the lines of three topics: First, the formal design characteristics of how to manage strategic foresight activities; second, the integration of foresight activities into strategic decision-making; and third, the way in which strategic-foresight activities are aligned with corporate strategy changes.

\subsubsection{Design Characteristics of the Management of Strategic-Foresight Activities}

According to our findings, there are three important design features of strategicforesight management: Structural design, i.e., the form in which foresight activities 
are managed within an organization; the structure of the process within which the strategic foresight activities are managed; and the methods that are part of strategicforesight activities.

Structural design: An in-depth analysis of the organizational dimensions of the five case-study companies revealed that there are three types of units that manage these firms' strategic-foresight activities: A specialized foresight unit, a partly specialized foresight unit, and a strategy unit (or other units) with an integrated foresight function. The DC STRG (about 35 employees) and DBR MTT (about 35 employees) have specialized foresight units. TUI CRI has a partly specialized foresight unit, whose five employees also perform tasks in the field of brands management. BASF SPC and Hilti CD have foresight functions that are integrated into the strategy/corporate-development unit. This finding resembles Becker's (2002) observational classification of "collecting posts," "observatories," and "think tanks." Specialized foresight units can be regarded as think tanks, while partly specialized units resemble observatories. The differences between Becker's finding and ours lie in Becker's range; he looked at all kinds of foresight activities, whereas this study focuses on highly formalized foresight activities.

Insight 1: Strategic foresight activities are structurally managed within an organization via one of three models: A specialized foresight unit, a partly specialized foresight unit, and a strategy unit or other units with an integrated foresight function.

Strategic foresight process design: The analysis of process sequences and structures revealed that three constitutive phases of the strategic-foresight process are important for managing strategic-foresight activities: The phases of initiation, modeling, and finalization. For example, in the initiation phase at BASF SPC, we discovered activities that follow an information push-and-pull logic: While the board expects regular input in the strategic-planning process, the company also offers, for instance, "innovation-scouting" and "trend research."

This threefold schema can be found in most of the relevant literature. However, in contrast to existing research, which describes linear processes (Voros 2003), we found that foresight processes usually occur in circular, iterative loops. The output of the activity is continually revised in a dialogue with other parties in the same phase or over several phases. The following two quotes demonstrate such circularity: "We developed our own planning philosophy. One shouldn't just produce papers and documents, but engage in an active strategic dialogue" (BASF I1); and "Interdisciplinarity as well as the interaction with our [foresight] customers has definitely increased, particularly in those BU strategy workshops" (DBR I1).

These diverse feedback loops constitute an important basis for individual and organizational learning. The involved persons (re)construct and (re)interpret developments and sensitivities in the firm's environment. The feedback loops provide the process with the required variability and flexibility: The initial specifications related to task, content, and method can be aligned according to the learning effects during the project's progress, while the basic organizational structures do not change. From an organization-theory perspective, foresight 
processes can therefore be seen as types of "semi-structures" (Brown and Eisenhardt 1997). Linear process models, as presented in previous studies, therefore run the risk of being overly fixed on a sequential process with a clearly defined beginning and end, and, in most cases, on a formal process-output. Such a reductionist view may hamper interpretation and implementation in the practical context, and thereby impede or even prevent the foresight process's performance.

Insight 2: Strategic foresight processes consist of three constitutive phases that are important for the management of strategic foresight activities: The initiation, modeling, and finalization phases. However, in contrast to the linear models proposed in previous studies, these phases occur in circular, iterative loops on different activity levels.

Methods in strategic-foresight activities: Regarding the methods used in strategic-foresight activities, this study confirms the results of previous studies. In recent years, companies have intensified the use of both qualitative and participative methods (Burmeister et al. 2002). "The spectrum of our [foresight] methods has been extended. Originally, we mainly used traditional techniques, like market research, trend extrapolation, and econometrics. Over time, many more soft methods have been introduced. (...) ... and also scenarios and portfolio management have become much more important to us." (BASF I1)

The significant increase in the use of contingency methods, such as scenario techniques and wild cards, can be attributed to increasing difficulties in forecasting a company's environment. Nevertheless and somewhat unexpectedly, forecasts and projections still play a prominent role, mainly because key decision makers still request them. Whether the reasons behind this request are based on the "fallacy of prediction" as proclaimed by Mintzberg (1994: 110), or on the decision makers' motives, is a question that remains open, and would offer an interesting starting point for future research.

Insight 3: Within strategic foresight activities, the use of qualitative and participative methods is increasing in comparison to the use of other forecast and projection methods.

\subsubsection{Integration of Strategic-Foresight Activities into Strategic Decision-Making}

We expected that foresight activities would have no specific foci, since their aim is to gain a better understanding of future developments. However, we discovered that strategic foresight is integrated into strategic decision-making processes on the basis of one of two foci: with a focus either on innovation or on planning (e.g., in a strategic-planning department). With their foresight activities, companies usually aim to achieve multiple objectives that relate to supporting either planning or 
innovation tasks. "Today we closely examine the relevant Mega-Trends. The insights gained are used in strategic planning or for innovation purposes" (BASF I3).

However, depending on the overall strategic decision-making support of their strategic-foresight activities, the five case-study companies were placed on a continuum between "main focus on innovation" and "main focus on planning." "We need to know how our business will evolve over the next years. (...) Yes, foresight was intended to be a strategic tool to systematically support the corporate strategy, to find the right direction" (TUI I1).

Of the five case studies, DaimlerChrysler were found to have a primary innovation focus. This is due to their shift toward the support of product development over the last few years. In contrast, Hilti were found to have a primary focus on planning, where the strategic-foresight activities mainly serve to develop a corporate strategy in the context of the regular strategic-planning cycle. Institutional integration of foresight activities into BASF's strategy dialogue has also resulted in a strong focus on planning. Similar to Hilti, the BASF corporate-strategy department controls the process. Compared to these companies, Deutsche Bank is located in the middle of the continuum, between planning and innovation. Both strategic-planning decisions and marketing decisions are supported. Deutsche Bank's foresight team is both a specialized foresight unit and an integral part of the corporate-support function. Finally, strategic-foresight activities at TUI also have a strong innovation orientation. While the unit supports corporate strategy development, it focuses more strongly on corporate-innovation support.

If the main focus of strategic-foresight activities is to support innovation projects and new strategic initiatives in the corporation, the results are accessible by a wide clientele inside and partly outside the company. The main purpose is to support strategic-innovation decisions that relate chiefly to product, marketing or distribution decisions on a business-unit level. It includes the exploration of new business models: the "opening" of strategic thinking and acting to identify, develop, and evaluate new growth potentials. "It is crucial to transform the old business model into a new one. And therefore I need to know the relevant trends in our business environment, so that I can inform our board: 'Be careful, the market is changing, we need to establish a new business model."' (TUI I3). Formal outputs are either innovation stimuli in the form of topics, ideas, concepts, etc., or concrete recommendations. These activities are typically managed and controlled by foresight units with an interdisciplinary and broad-topic orientation, as well as a relatively high level of specialization (e.g., think tanks).

If the focus of strategic-foresight activities is on planning, those activities are closely linked to the annual strategic-planning process in terms of both organizational design and methods. They primarily support the preparation of decisionmaking and the decision-making itself. Exploitation is a central function of such strategic-foresight activities, with a focus on planning: The "closing" of strategic thinking and acting in order to find a strategic consensus and decide on complex strategic issues. Usually, only a limited number of specialized people have access to the information - usually a company's strategy committee. These activities are typically managed and controlled by corporate-strategy units with an integrated foresight function. "Together with the board, we established a strategic dialogue 
process, starting with the initializing scenarios. They gave us a rough picture of the future: What markets will look like, how we see our future, what future businesses there will be. (...) These pictures were given to the units and they could comment on them. (...) Based on this interactive dialogue process, the new strategies were developed" (BASF I1).

Insight 4: Firm-wide, strategic-foresight activities support strategic decisionmaking, with a main focus either on innovation and exploration or on planning and exploitation.

\subsubsection{Change and Alignment of Strategic-Foresight Activities}

Context and antecedents of change and alignment: Our findings show that strategic-foresight activities are subject to substantial context-dependent change. While we expected this, still it was surprising how substantial these alignments proved to be. All five case-study companies experienced a fundamental and context-dependent change in their foresight activities over the past few years.

The comparative case-study analysis reveals two central firm-internal contingencies of strategic-foresight activities: The content-related openness of the corporate strategy (diversification vs. focusing), and the openness of the corporate strategic-planning process (outside vs. inside orientation). Changes in these contingencies induce the alignment of foresight activities, because the patterns of foresight-knowledge demand and the openness of decision makers toward foresight activities change. Consequently, in recent years, foresight activities have experienced substantial change and realignment as a consequence of increasing pressure to innovate and diversify on the one hand, and on the other of systematization and the increased outside-orientation of strategic planning and decision-making. "There is a link to the strategy review [of 1996]. During that period, we developed our new 'Champion-3 C-strategy.' And, as a consequence, we systematically extended our strategy process. (...) At the same time, we also improved our capabilities in the strategy unit regarding our aspirations and skills to think and act strategically. (...) This is related to the competences of the strategy team working on the [foresight] topics as well as to the competences to work on such long-term issues and questions. (...) We have heightened our awareness" (Hilti I1).

Many of the content-related alignments we have seen are linked to portfoliorestructuring decisions. "The corporate portfolio is being mirrored in our daily work" (DC I2). Or: "The transformation toward the model "central research unit diversified technology group' implies that we tried to mirror the variety of our diversified group." (DC I1). This restructuring can lead to an extension and broadening of foresight activities, when foresight is linked to a growth strategy like internationalisation. "Due to the increasing relevance of globalization, our foresight-related issues have been expanded. The topics have become more internationally oriented" (BASF I1). Or: "The continuous internationalization of our work is due to the internationalization of our group, including the merger with 
Chrysler in 1998. (...) We have become very internationalized, also regarding the languages and cultural understanding of our staff" (DC I2). However, portfoliorestructuring decisions can also result in a decrease in foresight activities, due to divestments: "We have been shrinking since 2001, 2002. There are two reasons for this. First, we have lost different non-automotive customers, due to the concentration on our automotive core business - we aren't working for the aerospace industry, AEG, and other companies anymore. (...) The projects for nonautomotive businesses just vanished, because those [process] customers have left, have been sold, or just changed their business. Second, we have been subject to different cost-cutting programs of our group." (DC I2)

Moreover, it is important to note that changes in the two contingencies themselves have always been dependent on a broader context: New customer trends, increased competition, continuing internationalization, and the increased pressure from capital markets to make profits have induced strategic diversification. Increased systematization and the outside orientation of strategic planning, for example, have resulted in the introduction of active portfolio management, the implementation of new management systems, a change in top management, and the strategic renewal of the entire company.

Furthermore, the general aspects that are related to increasing environmental complexity and dynamics influence the two contingencies. Examples are the terror attacks of 11 September 2001, the bursting of the new economy bubble, and the recent global financial and economic crisis. These developments have raised awareness of the economic environment, demonstrated the limits of prediction, and furthered the openness of strategic planning and decision-making. "The massive decline in both, the US economy and the new economy, has led to an increased awareness that we can't just extrapolate simple trends without an extensive environmental analysis. Otherwise, this can be misleading. It has fostered the willingness to abandon naive forecasts, like an exact prediction of the GDP growth rate, in favor of thinking in ranges and scenarios. This is one of the reasons why the management established a specialized trend-and-futures studies unit in the company" (DBR I1). At the same time, the stronger interrelatedness and increased unpredictability of markets lead to a risk-strategy diversification.

Insight 5: Strategic-foresight activities are subject to substantial context-dependent change. Two central, firm-internal contingencies of strategic-foresight activities are the content-related openness of the corporate strategy (diversification vs. focusing), and the openness of the strategic-planning process (outside vs. inside orientation). Changes in these contingencies induce the alignment of the foresight activities, as the patterns of demand for foresight knowledge and decision makers' openness toward foresight activities change.

The comparative case study shows that foresight activities are aligned with their process context via either innovation-oriented or planning-oriented openings. In most of the cases, we observed a process opening. In half of the cases, the opening was innovation-oriented; that is, the foresight activities were aligned with the support of strategic decision-making in various strategic initiatives and innovation 
projects. In the other half of cases, the opening was planning-oriented, and led to a closer link between foresight activities and strategic-planning process.

Foresight capacity and methods: During the observed time period, the case-study companies generally extended their capacity for foresight activities in different ways. The three most general methods are, first, to increase the foresight department's size; second, to increase the amount of resources and number of experts used in foresight activities; and, third, to involve the strategic decisionmakers more closely in strategic foresight activities.

In most companies, the portfolio of foresight methods was greatly enlarged. Against a background of increasing pressure to innovate and diversify, systematization, and the increased outside orientation of strategic planning and decisionmaking, three main developments were observed: First, there was an increase in the use of qualitative methods that are closely related to the customer and trend analysis in the context of strategic innovation, for example, for idea generation and businessmodel innovation; second, there was an increase in the use of participative and discursive methods either as a condition of strategic decision-makers or due to increased participation by the broader public; and third, there was an increase in the use of contingency methods, such as the scenario technique and wild cards. "The moment of surprise became much more important. This is why we use the wild-card technique (...). Nobody was thinking about the implications of disturbing factors like the 'bird flu' or 'Catharina' [a hurricane]. The awareness for those factors and the fact that they can become true has increased tremendously. You just need to be aware of such things if you claim to be No. 1. And of course, this influences our risk perception, too" (BASF I1).

In the case-study companies, for the most part, we observed a broader and more long-term orientation with regard to topics. In light of the increasing complexity and dynamics in the environment, this finding is surprising. The topical expansion not only included new, clearly defined topic areas, but also tools targeted specifically at detecting blind spots - in both positive and negative ways. An example is the innovation scouting team located in BASF's strategic-planning department, or in its "Strategic BASF Think Tanks Network" (STRATNET). This team expanded BASF's classical early warning system, BASIKS, to include blind spots. Moreover, it consisted of a worldwide network of external think tanks and an internal circle of BASF experts.

The timing of change and alignment: We found that fundamental change was induced in strategic-foresight activities by a radical and sudden change in corporate strategy. "We strive for a high consistency between the corporate strategy and the strategy process" (TUI I1). Yet surprisingly, the alignment process that followed was evolutionary. This means that the alignment process had a long duration and followed a continuous learning and optimization process. Usually, no specific change organization was set up to steer the change. Change management was the exception. Change and alignment were implicit and occurred due to the continuous adoption of new strategic requirements and goals.

Insight 6: Fundamental change in Strategic-foresight activities is induced by a radical and sudden change in the corporate strategy. The subsequent alignment 
process is continuous, takes relatively long, and follows a constant learning and optimization process.

However, the opposite causality can also be expected, i.e., strategic foresight may result in corporate strategy changes. "We can see today, how our results flow into the new products and strategies" (DC I1).

\subsubsection{Success Factors of Change and Alignment in Strategic-Foresight Activities}

From the case studies, we deduced the success factors of alignment in strategicforesight activities. These factors are summarized in Fig. 4.1.

The success factors are specifically focused on change. They relate to the successful implementation of alignment processes in foresight activities and not to the strategic-foresight activities as such. With regard to all the success factors, the foresight staff's personal characteristics and the strategic-foresight activities' cultural components seem especially important, since facing the future with its inherent uncertainty requires openness and a desire to learn and change. "You need a lot of curiosity and creativity to design and implement a well-working foresight process for your company..., to provide the right inputs" (TUI I1). More than any other change process, the successful alignment of foresight activities with corporate strategy requires committed and convincing change agents, in both the foresight staff and top management.

Foresight units have to be efficient and effective. "Our effectiveness has been significantly increased, because today we are able to provide information to support earlier phases of the strategy process" (BASF I1). Or: "The most critical success factor is our organizational flexibility, including our ability to deepen our knowledge about various fields within short time-frames. It was just about skilled and adaptive employees that were highly motivated to tackle new questions and issues" (DC I3). However, there is also the yearly challenge of approving the budget to finance a team that is able to deliver professional foresight services. "The fact that the foresight projects are subject to an increasing need for efficiency is a crucial factor. Compared to the situation 10 years ago, our customers are asking for the same outputs whereas expenses need to be reduced by more than $50 \%$. This circumstance just left its traces" (DC I2).

\subsection{Discussion}

This paper provides an understanding of the management of strategic-foresight activities within large multinational corporations by describing, first, how those enterprises scan and anticipate their current and future environment by means of formal observation and analysis processes; and second, how these formal foresight activities are integrated into the strategic decision making; and third, how these 


\begin{tabular}{|c|c|}
\hline Gafegory & Success factors \\
\hline $\begin{array}{l}\text { Participation in } \\
\text { change }\end{array}$ & $\begin{array}{l}\text { - Development / maintenance of a powerful project team } \\
\text { - Participation of "...enough people, who want to drive it". } \\
\text { - High engagement of change participants, individual "drive" }\end{array}$ \\
\hline Timing of change & - Choosing the right point in time for adaptation measures \\
\hline $\begin{array}{l}\text { Professional/ } \\
\text { foresight } \\
\text { competence }\end{array}$ & $\begin{array}{l}\text { - Possibility of using "Inhouse competence" in project management } \\
\text { - Creation of an improved technical understanding } \\
\text { - Fast generation of environment and market knowledge, cultural competence } \\
\text { - Targeted development of methods competence }\end{array}$ \\
\hline $\begin{array}{l}\text { Flexibility } \\
\text { leaming ability of } \\
\text { the foresight team }\end{array}$ & $\begin{array}{l}\text { - Using the organizational flexibility of the team, ability to self-organize } \\
\text { - Preservation of the curiosity and creativity of the team } \\
\text { - Highlearning ability, mental flexibility }\end{array}$ \\
\hline $\begin{array}{l}\text { Culture of the } \\
\text { foresight team }\end{array}$ & $\begin{array}{l}\text { - Open-to-change culture } \\
\text { - Open and trustful working environment in the team } / \text { in the unit } \\
\text { - Persistence, assertiveness in change }\end{array}$ \\
\hline $\begin{array}{l}\text { Organization. } \\
\text { structure }\end{array}$ & $\begin{array}{l}\text { - Systematic openess of the organizational structures } \\
\text { - High flexibilty and adaptiveness of the system }\end{array}$ \\
\hline $\begin{array}{l}\text { Interaction with } \\
\text { strategic decision } \\
\text { makers }\end{array}$ & $\begin{array}{l}\text { - Intensificatlon of the internal communication, creation of firm-internal presence } \\
\text { - Creation of transperency and comprehensibility } \\
\text { - Focused positioning of the foresight unit / foresight activities in the firm } \\
\text { - Creation of acceptance of new thinking / new methods } \\
\text { - Maintaining political neutrality and content openness }\end{array}$ \\
\hline $\begin{array}{l}\text { Support by top } \\
\text { management }\end{array}$ & $\begin{array}{l}\text { - Firm-internal legitimization through commitment of top management } \\
\text { - Comprehensive support by chief executive officer } \\
\text { - Manegement provides enough latitude for action and change } \\
\text { - Menagement's trust in change participants/agents }\end{array}$ \\
\hline
\end{tabular}

Fig. 4.1 Success factors of alignment in strategic-foresight activities

formal foresight activities are changed and aligned with corporate strategic changes in the firm. These research findings contribute to a comprehensive understanding of the evolving concept and phenomenon of strategic foresight. Moreover, they can be used in model-based management to draw up more realistic models.

In line with "qualitative" research methodologies, we drew on only a small number of interviews. These were rigorously analyzed and led to a detailed, conceptually rich description of a small sample of the empirical reality. We are confident that we have succeeded in identifying the most relevant issues. While we deem our findings to have yielded important insights, further research could build on them and test them, based on data that are statistically more representative. This study has focused on formal, organizational foresight activities in companies, as distinct from informal foresight. Evidently, any kind of forward-looking strategic thinking is a fundamental part of everyday strategic management.

Moreover, we studied the management of foresight activities by using a comprehensive approach, i.e., studying the entire management of foresight activities and covering all relevant aspects. While this has allowed us, as a first 
step, to provide a relatively complete descriptive picture of the management of foresight activities, our broad approach did not allow us to further investigate any of our insights into the management of foresight activities. Therefore, future research could look into any of the sub-aspects of our insights into the specific type of management presented in this paper. For example, it would be fruitful to investigate in more detail the temporal aspects and dynamics of change, as well as alignment processes, in foresight activities. Moreover, we believe that our insights into the alignment of these activities to changes in corporate strategy could be developed into a theory of strategic foresight-activity alignment.

Despite these limitations, this study contributes insights that improve our understanding of the management of strategic-foresight activities, in particular their integration into strategic decision-making and their change and alignment in response to changes in corporate strategy.

\section{References}

Aaltonen M, Sanders I (2005) Complexity as a sensemaking framework for methodology. In: Aaltonen M, Barth T, Casti JL, Mitleton-Kelly E, Sanders TI (eds) Complexity as a sensemaking framework. Finland Futures Research Centre, Turku, pp 21-37

Ansoff HI (1965) Corporate strategy: an analytical approach to business policy for growth and expansion. McGraw-Hill, New York

Ansoff HI (1980) Strategic issue management. Strateg Manag J 1(2):131-148

BASF, I1, I2, I3. Interview BASF's strategic planning \& controlling.

Becker P (2002) Corporate foresight in Europe: a first overview. University of Bielefeld, Institute for Science and Technology Studies

Becker WM, Freeman VM (2006) Going from global trends to corporate strategy. McKinsey Quart 3:17-19

Beer S (1972) Brain of the firm. The Penguin Press, London

Brown SL, Eisenhardt KM (1997) The art of continuous change: linking complexity theory and time-paced evolution in relentlessly shifting organizations. Adm Sci Q 42(1):1-34

Burmeister K, Neef A, Albert B, Glockner H (2002) Z_Dossier 02: Zukunftsforschung und Unternehmen. Praxis, Methoden, Perspektiven

Burmeister K, Neef A, Beyers B (2004) Corporate Foresight - Unternehmen gestalten Zukunft. Murmann, Hamburg

Chakravarthy BS, White RE (2002) Strategy process: forming, implementing and changing strategies. In: Pettigrew A, Thomas H, Whittington R (eds) Handbook of strategy and management. Sage, London, pp 182-205

Chakravarthy BS, Müller-Stewens G, Lorange P, Lechner C (2003) Defining the contours of the strategy process field. In: Chakravarthy B, Müller-Stewens G, Lorange P, Lechner C (eds) Strategy process: shaping the contours of the field. Blackwell, Oxford, pp 1-17

Collins JC, Porras JI (1996) Building your company's vision. Harv Bus Rev Sept-Oct: 65-77

Costanzo LA, MacKay RB (2009) Handbook of research on strategy and foresight. Edward Elgar, Cheltenham

Cunha MPE, Palma P, Costa NGD (2004) Tracking changes in organizational foresight. Paper presented at the 2nd international conference on organizational foresight, Glasgow

DBR I1 Interview Deutsche Bank (Research) Macro Trends Team

DC, I1, I2, I3. Interview DaimlerChrysler Society and Technology Research Group 
Dutton JE, Duncan R (1987) The creation of momentum for change through the process of strategic issue diagnosis. Strateg Manag J 4:307-323

Dutton JE, Ottensmeyer E (1987) Strategic issue management systems: forms, functions, and contexts. Acad Manage Rev 12(2):355-365

Eisenhardt KM (1995) Building theories from case study research. In: Huber GP, Van de Ven AH (eds) Longitudinal field research methods: studying processes of organizational change. Sage, Thousand Oaks, pp 65-90

El Sawy OA, Pauchant TC (1988) Triggers, templates and twitches in the tracking of emerging strategic issues. Strateg Manage J 9(5):455-473

Elenkov DS (1997) Strategic uncertainty and environmental scanning: the case for institutional influences on scanning behavior. Strateg Manage J 18(4):287-302

Espejo R, Schumann W, Schwaninger M, Bilello U (1996) Organizational transformation and learning: a cybernetic approach to management. Wiley, Chichester

Godet M (2001) Creating futures. Scenario planning as a strategic management tool. Economica, London

Gordon TJ (1994) Methods frontiers and integration: UNDP/African Futures

Grosu D (2007) Visions and visioning in foresight activities. Paper presented at the COST A22, Athens

Gruber M, Venter C (2006) Die Kunst, die Zukunft zu erfinden. Zeitschrift für betriebswirtschaftliche Forschung 58(11):958-984

Hilti I1 Interview Hilti Corporate Development

Horton A (1999) A simple guide to successful foresight. Foresight 01(01):5-9

Hoskisson RE, Hitt MA, Wan WP, Yiu D (1999) Theory and research in strategic management: swings of a pendulum. J Manage 25(3):417-456

Kreibich R, Schlaffer A, Trapp C, Burmeister K (2002) Zukunftsforschung in Unternehmen. Sekretariat für Zukunftsforschung, Berlin

Lederman LL (1984) Foresight activities in the U.S.A.: time for a re-assessment? Long Range Plan $17(3): 41-50$

Lüdeke MKB (2007) Bridging qualitative and quantitative methods in foresight. Paper presented at the COST A22, Athens

Major EJ, Cordey-Hayes M (2000a) Engaging the business support network to give SMEs the benefit of foresight. Technovation 20(11):539-603

Major EJ, Cordey-Hayes M (2000b) Knowledge translation: a new perspective on knowledge transfer and foresight. Foresight 2(4):411-423

Major EJ, Asch D, Cordey-Hayes M (2001) Foresight as a core competence. Futures 33:91-107

Mintzberg H (1994) The fall and rise of strategic planning. Harv Bus Rev Jan-Feb: 107-114

Müller A, Müller-Stewens G (2009) Strategic foresight. Trend- und Zukunftsforschung in Unternehmen - Instrumente, Prozesse, Fallstudien. Schäffer-Poeschel, Stuttgart

Oomens MJH, van den Bosch FAJ (1999) Strategic issue management in major European-based companies. Long Range Plann 32(1):49-57

Roxburgh C (2009) The use and abuse of scanrios. Mc Kinsey Quarterly, Nov: 1-10

Ruff F (2006) Corporate foresight: integrating the future business environment into innovation and strategy. Int J Technol Manage 34(3/4):278-295

Schwaninger M (2001) Intelligent organizations: an integrative framework. Syst Res Behav Sci $18(2): 137-158$

Schwaninger M (2009) Intelligent organizations: powerful models for systemic management. Springer, Berlin/Heidelberg

Schwaninger M (2010) Model-based management (MBM): a vital prerequisite for organizational viability. Kybernetes 39(9/10):1419-1428

Schwartz P (1991) The art of the long view: planning for the future in an uncertain world. Doubleday, New York

Schwarz JO (2006) The future of futures studies: a delphi study with a German perspective. Shaker, Aachen 
Steinle C, Ahlers F, Rutter C (2000) Zukunftsforschung und Strategieentwicklung in Finanzdienstleistungsunternehmungen: Konzept, empirisches Schlaglicht und Gestaltungsoptionen. Kredit und Kapital 4:571-604

Slaughter RA (1995) The foresight principle - cultural recovery in the 21 st century. Adamantine Press, London

Strauss AL, Corbin J (1990) Basics of qualitative research: grounded theory procedures and techniques. Sage, Newbury Parks

Suarez FF, Oliva R (2005) Environmental change and organizational transformation. Indus Corporate Change 14(6):1017-1041

Thomas JB, McDaniel RR (1990) Interpreting strategic issues: effects of strategy and the information-processing structure of top management teams. Acad Manage J 33:286-306

Tsoukas H, Shepherd J (2004) Managing the future: foresight in the knowledge economy. Blackwell, Oxford

TUI I1, I3 Interviews TUI Corporate Research \& Innovation

Van der Duin P (2006) Qualitative futures research for innovation. Eburon Academics, Delft

Van der Heijden K (2004) Insights into foresight (afterword). In: Tsoukas H, Shepherd J (eds)

Managing the future - foresight in the knowledge economy. Blackwell, Oxford, pp 204-211

Voros J (2003) A generic foresight process framework. Foresight 5(3):10-21

Wack P (1985) Scenarios: shooting the rapids. Harv Bus Rev Nov-Dec: 139-150 